\title{
Transforming growth factor $\beta$-induced epithelial-mesenchymal transition increases cancer stem-like cells in the PANC-1 cell line
}

\author{
HUI WANG ${ }^{1 *}$, JUNLI WU $^{2 *}$, YE ZHANG $^{1}$, XIAOFENG XUE $^{1}$, DONG TANG $^{1}$, ZHONGXU YUAN $^{1}$, \\ MINYONG CHEN ${ }^{1}$, JISHU WEI ${ }^{2}$, JINGJING ZHANG ${ }^{3}$ and YI MIAO $^{2}$ \\ ${ }^{1}$ Laboratory of General Surgery; ${ }^{2}$ Department of Surgery, The First Affiliated Hospital of Nanjing Medical University; \\ ${ }^{3}$ Jiangsu Province Academy of Clinical Medicine Institute of Tumor Biology, Nanjing 210029, P.R. China
}

Received August 7, 2011; Accepted October 11, 2011

DOI: $10.3892 / \mathrm{ol} .2011 .448$

\begin{abstract}
The epithelial-mesenchymal transition plays a crucial role in the progression of pancreatic cancer. The aim of this study was to examine the possible association between the epithelial-mesenchymal transition and cancer stem-like cells in pancreatic cancer. We used transforming growth factor $\beta$ to induce an epithelial-mesenchymal transition. The proportion of pancreatic cancer stem-like cells was measured and sorted by flow cytometry. The expression of markers was measured by quantitative PCR and Western blot analysis. Cell cycle distribution was assessed by flow cytometry. We evaluated the migration and invasion activity by Transwell tests. The proportion of pancreatic cancer stem-like cells was significantly increased following transforming growth factor $\beta$ treatment. Cells were sorted in culture, the cancer stem-like cells exhibited a higher degree of epithelial-mesenchymal transition and demonstrated upregulation of vimentin, a mesenchymal phenotypic marker, compared to the CD44 CD24- cells. Pancreatic cancer stem-like cells exhibited greater invasion and migration activity in vitro compared to the CD44-CD24- cells. These results suggested a direct link between epithelial-mesenchymal transition and cancer stem-like cells in pancreatic cancer.
\end{abstract}

\section{Introduction}

Pancreatic cancer is the fourth most common cause of mortality from cancer in the USA (1). Due to its early invasion and metastasis, this cancer is typically diagnosed at a late stage. With a 5-year survival rate of $1-4 \%$ and a median survival period of 4-6 months, the prognosis of patients with

Correspondence to: Dr Yi Miao, Department of General Surgery, The First Affiliated Hospital of Nanjing Medical University, 300 Guangzhou Road, Nanjing 210029, P.R. China

E-mail: miaoyi@njmu.edu.cn

${ }^{*}$ Contributed equally

Key words: transforming growth factor $\beta$, epithelial-mesenchymal transition, pancreatic cancer, cancer stem-like cell, migration, invasion pancreatic cancer remains poor (2-7). Intensive molecular studies of pancreatic cancer are key to solving these problems.

Previous studies showed that the epithelial to mesenchymal transition (EMT) is an important process in tumor progression and metastasis in pancreatic cancer $(8,9)$. EMT is characterized by the loss of epithelial characteristics and the acquisition of a mesenchymal phenotype, which increases the invasion and migration activity of cancer cells (10-14). Growth factors, such as transforming growth factor $\beta$ (TGF- $\beta$ ) and epidermal growth factor, are currently used to induce EMT $(15,16)$.

Mounting evidence shows that cancer stem cells (CSCs) play a significant role in tumor growth and propagation as they are capable of self-renewal and the production of differentiated progeny (17-20). Pancreatic CSCs were initially defined by their simultaneous expression of CD44, CD24 and EpCAM (21). Compared with other pancreatic cancer cells, CD $44^{+} \mathrm{CD} 24^{+} \mathrm{ESA}^{+}$ cells are the most highly tumorigenic. Injection of as few as 100 cells results in tumor formation in immunodeficient, non-obese, diabetic/severe combined immunodeficient mice. Increased resistance of CSCs to standard chemotherapy has been shown in a number of tumor types (22-24). In their study, Mani et al (25) reported that EMT generates CSCs in breast cancer. In ovarian cancer, transfection with Snail and Snail2 led to increases of a CD $44^{+} \mathrm{CD} 117^{+} \mathrm{CSC}$ population, which had increased resistance to chemo- and radiotherapy (26).

In the present study, we examined the possible association between EMT and CSCs in pancreatic cancer. We used TGF- $\beta$ to induce EMT and measured the proportion of pancreatic CSCs by flow cytometry.

\section{Materials and methods}

Cell culture. Human pancreatic cancer cells, PANC-1, were obtained from the Shanghai Cell Bank (Shanghai, China) and propagated in our laboratory. All cells were cultured in Dulbecco's modified Eagle's medium (DMEM; HyClone Laboratories, Inc., UT, USA) supplemented with $10 \%$ fetal bovine serum (FBS; Gibco, Carlsbad, CA, USA) and 1\% penicillin/streptomycin.

Quantitative reverse transcription polymerase chain reaction ( $q R T-P C R)$. Total RNA was isolated using TRIzol reagent (Invitrogen; Carlsbad, CA, USA), according to the 
manufacturer's instructions and using the following PCR primers: E-cadherin sense: 5'- GCGATGGCGGCATTGTA-3', antisense: 5'-GAGAACGCATTGCCACATACA-3'; vimentin sense: 5'-CTGAACCTGAGGGAAACTAATC-3', antisense: 5'-GCAGAAAGGCACTTGAAAGC-3'; and $\beta$-actin sense: 5'-AGAAAATCTGGCACCACACC-3', antisense: 5'-TAGC ACAGCCTGGATAGCAA-3'. qRT-PCR was performed using an ABI PRISM 7000 Sequence Detection System (Applied Biosystems; Foster City, CA, USA) with SYBR Premix EX Taq (Takara; Dalian, China).

Western blot analysis. The protein content of cultured cells was determined using a bicinchoninic acid (BCA) Kit (Keygen; Nanjing, China). We resolved the protein with $10 \%$ SDS-PAGE and transferred it to polyvinylidene difluoride membranes. The membranes were blocked with $5 \%$ non-fat milk in Tris-buffered saline for $2 \mathrm{~h}$ and incubated overnight with primary antibodies against E-cadherin (Millipore; Bedford, MA, USA) and vimentin (Millipore). The membranes were then washed and incubated for $2 \mathrm{~h}$ with horseradish peroxidase-conjugated goat anti-rabbit or goat anti-mouse secondary antibody (Santa Cruz Biotechnology, Inc.; Santa Cruz, CA, USA). Antibodies were detected using an electrochemiluminescence kit (Pierce; Rockford, IL, USA).

Flow cytometry. To identify and isolate $\mathrm{CD} 44^{+} \mathrm{CD} 24^{+}$and CD44-CD24- cells, the cells were washed with phosphate-buffered saline (PBS), removed from the culture dish with $0.25 \%$ trypsin and ethylenediaminetetraacetic acid (EDTA), and suspended in culture medium containing 10\% FBS. The cells were stained with CD24-PE $(5 \mu \mathrm{l} / \mathrm{ml})$ and CD44-FITC $(1 \mu \mathrm{l} /$ ml) antibodies (eBioscience; San Diego, CA, USA). Cell cycle analysis was conducted using a BD FACSCalibur flow cytometer and fluorescence-activated cell sorting (FACS) using a BD FACSAriaII special order system.

Cell cycle assays. Cell cycle distribution was assessed by flow cytometry. Sorted CD $44^{+} \mathrm{CD} 24^{+}$and CD 44-CD24- cells were collected, washed with PBS and fixed in $70 \%$ ice-cold ethanol at $4^{\circ} \mathrm{C}$ overnight, then suspended in $500 \mathrm{ml}$ of PBS stained with $20 \mu \mathrm{g} / \mathrm{ml}$ propidium iodide and $1 \mathrm{mg} / \mathrm{ml}$ RNase.

Cell migration and invasion. For analysis of cell migration and invasion, $1 \times 10^{5}$ sorted tumor cells were seeded onto the upper side of 24-well Transwell plates, uncoated (for migration assays) or coated (for invasion assays) with $1 \mathrm{mg} / \mathrm{ml}$ Matrigel (BD Biosciences; Bedford, MA, USA). The chambers were $6.5 \mathrm{~mm}$ in diameter with an 8-mm pore size (Corning Life Sciences; Lowell, MA, USA). DMEM (600 $\mu$ l) supplemented with $10 \%$ FBS was added to the lower chamber. The cells were incubated for $24 \mathrm{~h}$ at $37^{\circ} \mathrm{C}$, and cells on the upper side were then removed with cotton swabs. Migrating or invading cells on the bottom of the membrane were stained with $0.1 \%$ crystal violet for $30 \mathrm{~min}$ at $37^{\circ} \mathrm{C}$. Penetrating cells were stained and counted under a microscope.

Statistical analysis. Data were presented as the means \pm standard deviation (SD). To compare the two groups, the Student's t-test was performed using SPSS 13.0. P<0.05 was considered to be statistically significant.

\section{Results}

TGF- $\beta 1$ induces EMT in pancreatic cancer cells. To determine whether cancer cells that have undergone an EMT are enriched with cancer stem-like cells, we used TGF- $\beta 1$, which is capable of inducing EMT in epithelial cells.

Cell morphology was assessed prior to and up to $72 \mathrm{~h}$ following TGF- $\beta 1$ treatment in PANC- 1 cells. TGF- $\beta 1$ induced EMT in PANC-1 cells. Fig. 1A shows that, when treated with TGF- $\beta 1$ (10 ng/ml), PANC-1 cells acquire a spindle-type morphology and that the number of cell-cell contacts are reduced (16).

We then examined the effects of TGF- $\beta 1$ on the mRNA and protein expression of EMT-related markers in the PANC-1 cells. As expected, TGF- $\beta 1$ treatment reduced the expression of the epithelial marker E-cadherin but increased the expression of the mesenchymal marker vimentin (Fig. 1B and C).

TGF- $\beta 1$-induced EMT increases cancer stem-like cells. To determine the effect of TGF- $\beta 1$-induced EMT on the population of stem-like cells, we used flow cytometry to analyze the cells prior to and following TGF- $\beta 1$ treatment, based on the expression of CD44 and CD24, two cell-surface markers whose expression in the $\mathrm{CD} 44^{+} \mathrm{CD} 24^{+}$configuration is associated with pancreatic CSCs. Fig. 2 shows that the number of cancer stem-like cells was significantly increased by $30 \%$ among 48 h-TGF- $\beta 1$-treated PANC1 cells compared with the controls. This increase was time-dependent and occurred concomitantly with morphological changes. It commenced $12 \mathrm{~h}$ following treatment and was maximal after $48 \mathrm{~h}$. Notably, the number of $\mathrm{CD} 44^{+}$pancreatic cancer cells was significantly increased by $73 \%$ compared with the controls, whereas the number of $\mathrm{CD} 24^{+}$cells was increased by $20 \%$. The increase in the number of $\mathrm{CD} 24^{+}$cells occurred later than that of the CD $44^{+}$cells.

$C D 44^{+} \mathrm{CD} 24^{+}$cells exhibit a higher degree of EMT. To determine whether $\mathrm{CD} 44^{+} \mathrm{CD} 24^{+}$cells exhibit phenotypes similar to CD44-CD24- cells, we first sorted CD $44^{+} \mathrm{CD} 24^{+}$ and $\mathrm{CD} 44^{-} \mathrm{CD} 24^{-}$pancreatic cancer cells by FACS into cell culture. The $\mathrm{CD} 44^{+} \mathrm{CD} 24^{+}$and $\mathrm{CD} 44^{-} \mathrm{CD} 24^{-}$cells both exhibited mesenchymal morphology similar to that of cells that have undergone EMT. Compared with the CD44-CD24- cells, the $\mathrm{CD} 44^{+} \mathrm{CD} 24^{+}$cells exhibited mesenchymal morphology more clearly and the number of cell-cell contacts were fewer (Fig. 3A). This difference in phenotype was observed following $24 \mathrm{~h}$ of cell culture.

To determine whether the $\mathrm{CD} 44^{+} \mathrm{CD} 24^{+}$and CD $44{ }^{-} \mathrm{CD} 24$ cells have varying gene expression profiles associated with EMT, we used qRT-PCR and Western blot analysis to measure the expression of EMT-associated markers. Western blot analysis showed a reduced expression of the epithelial marker E-cadherin but an increased expression of the mesenchymal marker vimentin in $\mathrm{CD} 44^{+} \mathrm{CD} 24^{+}$cells, compared with the CD44-CD24- cells. These results were confirmed by qRT-PCR analysis (Fig. 3B and C).

Cell cycle differences between $\mathrm{CD} 44^{+} \mathrm{CD} 24^{+}$and $\mathrm{CD} 44^{-}$ CD24- cells. We used flow cytometry to determine whether the differences between $\mathrm{CD} 44^{+} \mathrm{CD} 24^{+}$and $\mathrm{CD} 44^{-} \mathrm{CD} 24^{-}$cells sorted by FACS were a result of differences in cell cycle 
A
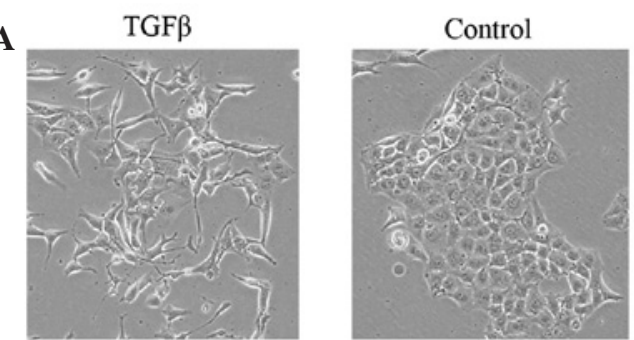

C

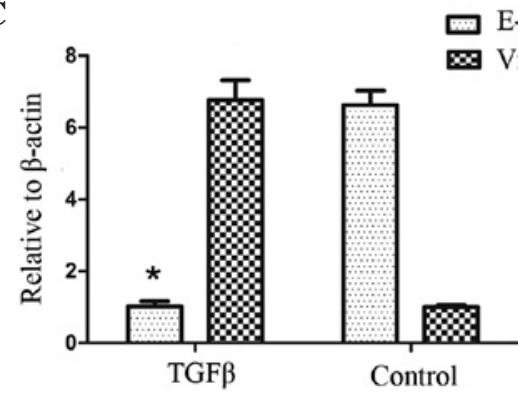

B

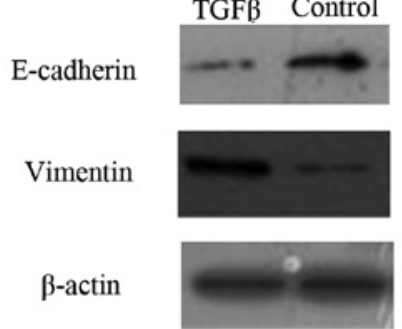

$120 \mathrm{kDa}$

$56 \mathrm{kDa}$

$43 \mathrm{kDa}$
$\mathbf{A}$

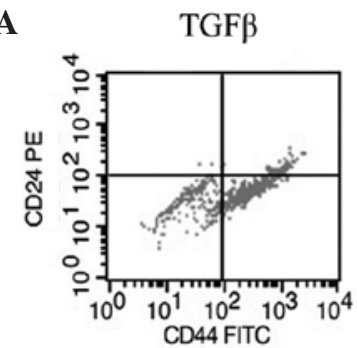

\begin{tabular}{cr} 
Quad $\%$ & Gated \\
\hline UL & 0.49 \\
UR & 9.54 \\
LL & 28.04 \\
LR & 61.93
\end{tabular}

Control
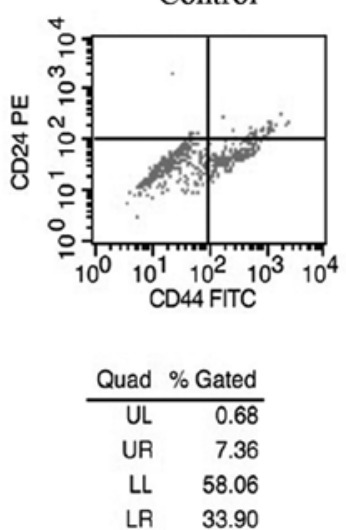

B

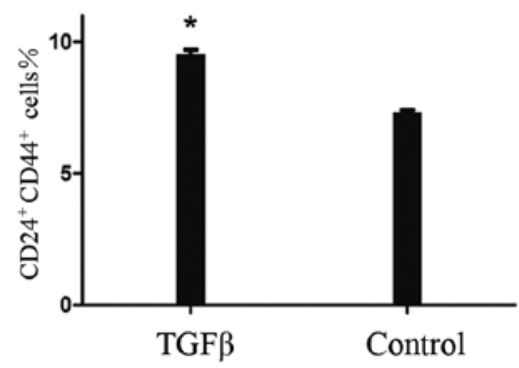

Figure 1. TGF- $\beta 1$ induces EMT in pancreatic cancer cells. (A) Phase contrast images of pancreatic cancer cells untreated and treated with transforming growth factor $\beta 1$ (TGF- $\beta 1,10 \mathrm{ng} / \mathrm{ml}$ ); magnification, $x 100$. PANC-1 cells under TGF- $\beta 1$ treatment acquired a spindle-type morphology. (B) Western blot analysis. $\beta$-actin was used as an internal loading control. (C) Quantitative RT-PCR with normalization to $\beta$-actin ( $\mathrm{P}<0.05)$. At both mRNA and protein levels, the expression of the mesenchymal marker, vimentin, was up-regulated by TGF- $\beta 1$ treatment. EMT, epithelial to mesenchymal transition; RT-PCR, reverse transcriptase polymerase chain reaction.

Figure 2. Flow cytometry of cell-surface markers CD24 and CD44 in PANC-1 cells treated with transforming growth factor $\beta 1$ (TGF- $\beta 1,10 \mathrm{ng} / \mathrm{ml})$ after $48 \mathrm{~h}$, and the controls. The number of stem-like cells (UR) was increased by $30 \%$ in TGF- $\beta 1$-treated PANC-1 cells compared with the controls. "P<0.05.

A

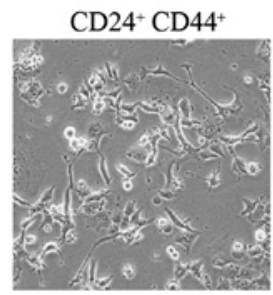

B

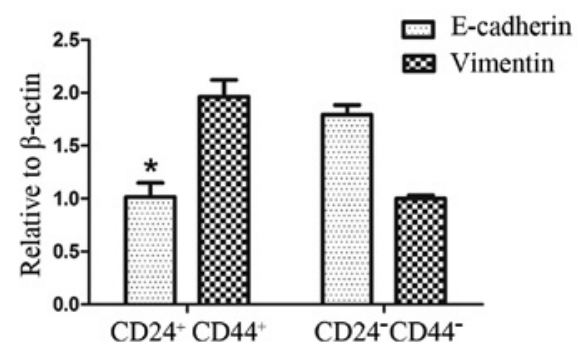

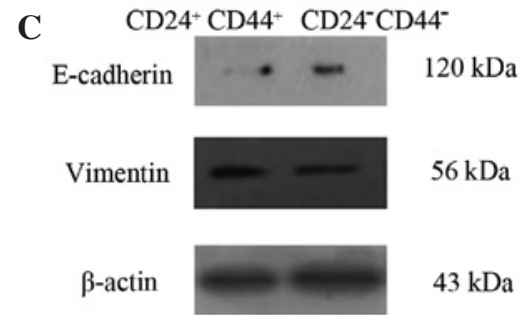

Figure 3. $\mathrm{CD} 44^{+} \mathrm{CD} 24^{+}$cells exhibit a higher degree of EMT. (A) Phase contrast images of $\mathrm{CD} 44^{+} \mathrm{CD} 24^{+}$and CD44-CD24- cells; magnification, $\mathrm{x} 100$. The $\mathrm{CD} 44^{+} \mathrm{CD} 24^{+}$cells exhibited mesenchymal morphology more clearly than the CD44CD24 cells. (B) Western blot analysis. $\beta$-actin was used as an internal loading control. (C) Quantitative RT-PCR with normalization to $\beta$-actin $\left({ }^{*} \mathrm{P}<0.05\right)$. Expression of the epithelial marker E-cadherin was reduced, whereas expression of the mesenchymal marker vimentin was increased in $\mathrm{CD} 44^{+} \mathrm{CD} 24^{+}$cells. EMT, epithelial to mesenchymal transition; RT-PCR, reverse transcriptase polymerase chain reaction. 

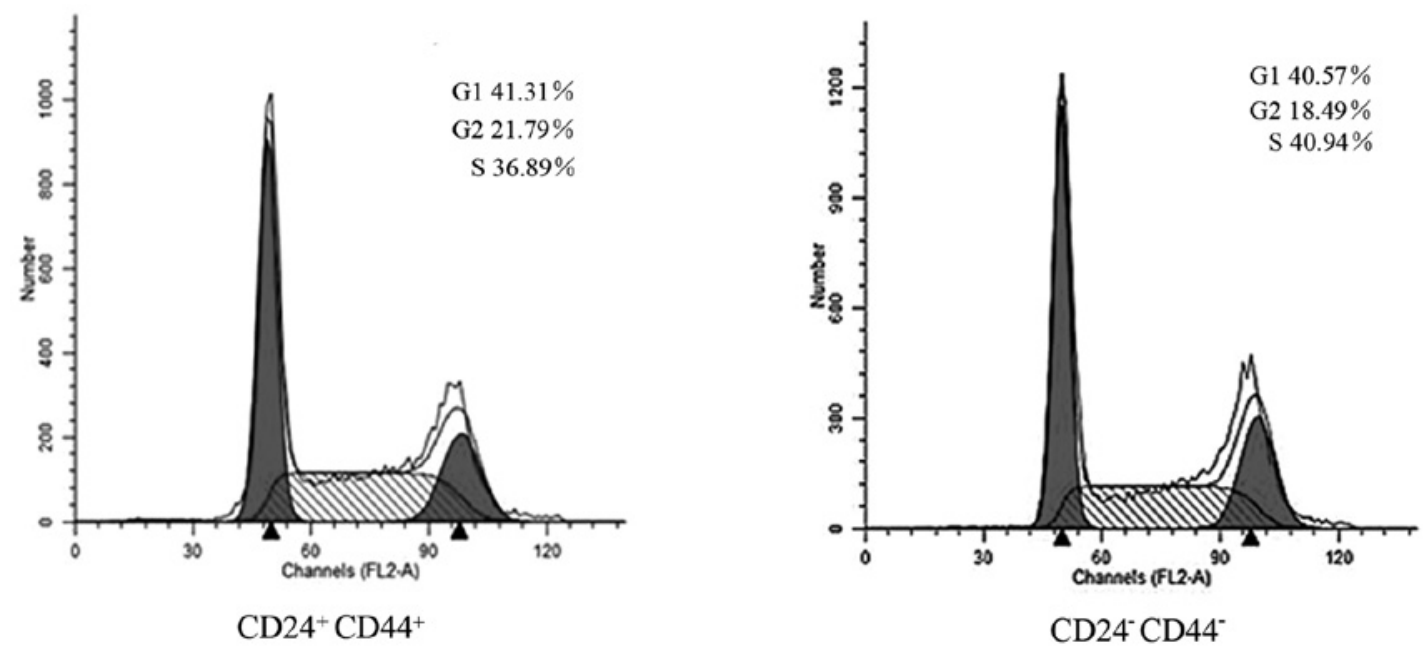

Figure 4. Cell cycle analysis of $\mathrm{CD} 44^{+} \mathrm{CD} 24^{+}$and $\mathrm{CD} 44^{-} \mathrm{CD} 24^{-}$cells. No significant differences were observed in the cell cycle distribution.

A

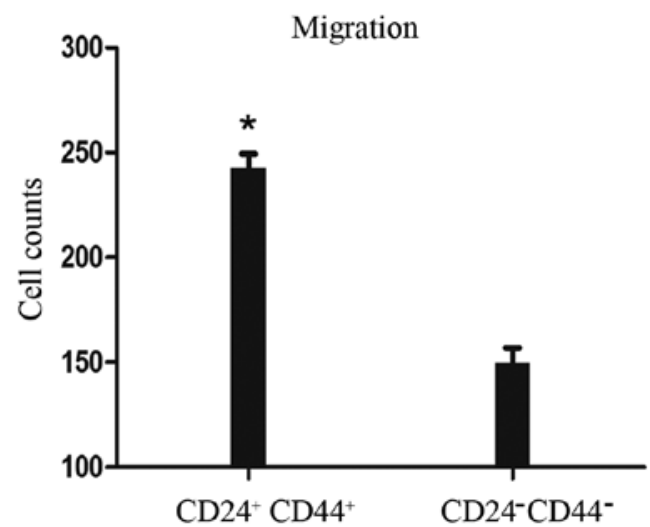

B

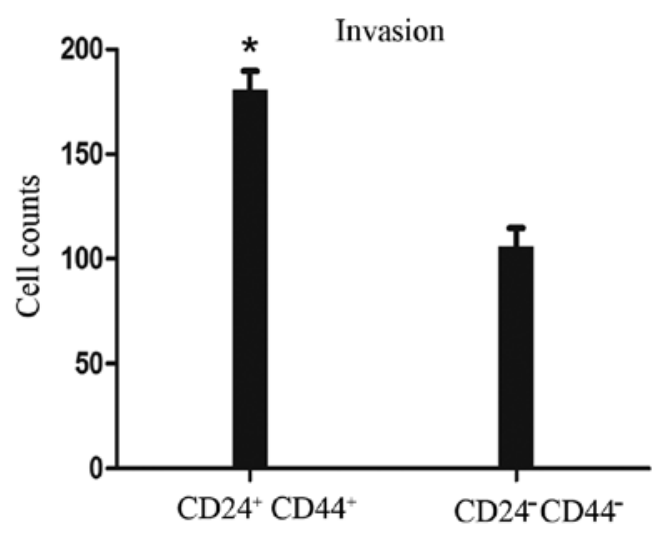

Figure 5. Invasion and migration of $\mathrm{CD} 44^{+} \mathrm{CD} 24^{+}$and $\mathrm{CD} 44^{-} \mathrm{CD} 24^{-}$cells. (A) Migration. (B) Matrigel invasion. $\mathrm{CD} 44^{+} \mathrm{CD} 24^{+}$cells showed prominent invasive and migration potential. Data are expressed as the means \pm SD from at least three independent experiments. ${ }^{*} \mathrm{P}<0.05$. SD, standard deviation.

distribution. Fig. 4 shows that there was no significant accumulation of the G0/G1 phenotype among the CD $44^{+} \mathrm{CD} 24^{+}$ cells $(41.31 \%)$ compared with the CD44-CD24- cells $(40.57 \%)$.

$C D 44^{+} C D 24^{+}$cells have greater migration and invasion activity. We evaluated cell migration and invasion to assess differences between $\mathrm{CD} 44^{+} \mathrm{CD} 24^{+}$and $\mathrm{CD} 44^{-} \mathrm{CD} 24^{-}$cells sorted by FACS. Fig. 5A shows that the migration ability of the $\mathrm{CD} 44^{+} \mathrm{CD} 24^{+}$cells was significantly increased by $60 \%$, compared with that of the CD44-CD24- cells. A Matrigel invasion assay was performed concomitantly. As shown in Fig. 5B, the invasive ability of the $\mathrm{CD} 44^{+} \mathrm{CD} 24^{+}$cells was significantly increased by $70 \%$, compared with that of the CD $44^{-}$CD24- cells. These results suggest that ${ }^{-} D 44^{+} \mathrm{CD} 24^{+}$ cells have greater migration and invasive activity than CD44 CD24- cells.

\section{Discussion}

The principal purpose of our study was to investigate the connection between pancreatic cancer stem-like cells and the EMT. The results show that: i) TGF- $\beta 1$-induced EMT increases cancer stem-like cells; ii) pancreatic cancer stem-like cells exhibit a higher degree of EMT; and iii) pancreatic cancer stem-like cells have greater migration and invasive activity in vitro.

Numerous studies have suggested that TGF- $\beta$ is overexpressed in pancreatic cancer (27) and that exposure of pancreatic cancer cells to TGF- $\beta$ leads to greater motility and invasive ability (28). We selected TGF- $\beta 1$ to induce EMT in pancreatic cancer cell lines based on the studies of Ellenrieder et al (16), in which five pancreatic cancer cell lines were treated with TGF- $\beta 1$ and three underwent EMT. We found that the morphology of the cells changed to spindle type and that the number of cell-cell contacts were reduced. qRT-PCR and Western blot analysis confirmed that the induction of EMT was successful.

Pancreatic CSCs were initially defined by their simultaneous expression of CD44, CD24 and EpCAM (21). CSCs are capable of self-renewal and the production of differentiated progeny. To investigate the effect of EMT on a population of stem-like cells, we used flow cytometry for analysis and sorting based on their expression of CD44 and CD24. We found that the number of stem-like cells was significantly increased in 
the TGF- $\beta 1$-treated group compared with the controls, and that the pancreatic stem-like cells exhibited a higher degree of EMT than the CD44-CD24- cells, which also have gene expression similar to that of cells that have undergone EMT. It remains unknown as to why the CD44-CD24- cells possess EMT features. Notably, the increase in the number of CD24+ pancreatic cancer cells was lower and occurred later than that of CD $44^{+}$pancreatic cancer cells. This phenomenon has not been reported in any previous publications and the reason remains unclear. During cell culture, the pancreatic cancer cells underwent EMT when the conditions altered (e.g., starving in serum-free medium), which increased the number of stem-like cells. This phenomenon demonstrates that EMT has a close relationship with pancreatic cancer stem-like cells, and that the number of cancer stem-like cells is not stable, changing under certain conditions. Our findings are not in agreement with the current CSC hypothesis.

We then evaluated the migration and invasive activity of the cancer stem-like cells. To the best of our knowledge, this is the first study to show increased migration and invasion in pancreatic cancer stem-like cells compared with the CD44 CD24- cells. The results may have significant implications for the treatment of pancreatic cancer, and explain the reason for the high mortality rate of patients with pancreatic cancer.

In conclusion, our study demonstrates that TGF- $\beta 1$-induced EMT increases stem-like cells in pancreatic cancer cells as pancreatic cancer stem-like cells exhibit a higher degree of EMT than CD44-CD24- cells, which also have gene expression profiles similar to that of cells that have undergone EMT, and display significant migration and invasion activity in vitro. Thus, pancreatic cancer stem-like cells have greater migration and invasive activity. Our results also indicate that pancreatic CSCs increase in number when the conditions deteriorate. As a result, we assume that CSCs are adaptable in pancreatic cancer, and that EMT is a process by which cancer cells increase their adaptability. Therefore, findings of the present study improve our understanding of the biological characteristics of pancreatic CSCs and provide new insights into EMT as an anti-cancer strategy.

\section{Acknowledgements}

This study was supported by the National Natural Science Foundation of China (No. 30972912).

\section{References}

1. Jemal A, Siegel R, Ward E, Hao Y, Xu J and Thun MJ: Cancer statistics. CA Cancer J Clin 59: 225-249, 2009.

2. Ahlgren JD: Chemotherapy for pancreatic carcinoma. Cancer 78: 654-663, 1996

3. Jemal A, Tiwari RC, Murray T, et al: Cancer statistics. CA Cancer J Clin 54: 8-29, 2004

4. Philip PA, Mooney M, Jaffe D, et al: Consensus report of the National Cancer Institute clinical trials planning meeting on pancreas cancer treatment. J Clin Oncol 27: 5660-5669, 2009.
5. Rosenberg L: Treatment of pancreatic cancer. Promises and problems of tamoxifen, somatostatin analogs, and gemcitabine. Int J Pancreatol 22: 81-93, 1997.

6. Rothenberg ML, Moore MJ, Cripps MC, et al: A phase II trial of gemcitabine in patients with 5-FU-refractory pancreas cancer. Ann Oncol 7: 347-353, 1996.

7. Warshaw AL and Fernandez-del CC: Pancreatic carcinoma. N Engl J Med 326: 455-465, 1992.

8. Nakajima S, Doi R, Toyoda E, et al: N-cadherin expression and epithelial-mesenchymal transition in pancreatic carcinoma. Clin Cancer Res 10: 4125-4133, 2004.

9. Ellenrieder V, Hendler SF, Ruhland C, Boeck W, Adler G and Gress TM: TGF-beta-induced invasiveness of pancreatic cancer cells is mediated by matrix metalloproteinase- 2 and the urokinase plasminogen activator system. Int J Cancer 93: 204-211, 2001.

10. Thiery JP: Epithelial-mesenchymal transitions in tumour progression. Nat Rev Cancer 2: 442-454, 2002.

11. Kang Y and Massague J: Epithelial-mesenchymal transitions: twist in development and metastasis. Cell 118: 277-279, 2004.

12. Thiery JP, Acloque H, Huang RY, et al: Epithelial-mesenchymal transitions in development and disease. Cell 139: 871-890, 2009.

13. Kalluri R and Weinberg RA: The basics of epithelial-mesenchymal transition. J Clin Invest 119: 1420-1428, 2009.

14. Zeisberg M and Neilson EG: Biomarkers for epithelial-mesenchymal transitions. J Clin Invest 119: 1429-1437, 2009.

15. Kabashima A, Higuchi $\mathrm{H}$, Takaishi $\mathrm{H}$, et al: Side population of pancreatic cancer cells predominates in TGF-beta-mediated epithelial to mesenchymal transition and invasion. Int $\mathrm{J}$ Cancer 124: 2771-2779, 2009

16. Ellenrieder V, Hendler SF, Boeck W, et al: Transforming growth factor betal treatment leads to an epithelial-mesenchymal transdifferentiation of pancreatic cancer cells requiring extracellular signal-regulated kinase 2 activation. Cancer Res 61: 4222-4228, 2001.

17. Reya T, Morrison SJ, Clarke MF and Weissman IL: Stem cells, cancer, and cancer stem cells. Nature 414: 105-111, 2001.

18. Al-Hajj M, Wicha MS, Benito-Hernandez A, Morrison S and Clarke MF: Prospective identification of tumorigenic breast cancer cells. Proc Natl Acad Sci USA 100: 3983-3988, 2003.

19. Hermann P, Huber S, Herrler T, et al: Distinct populations of cancer stem cells determine tumor growth and metastatic activity in human pancreatic cancer. Cell Stem Cell 1: 313-323, 2007.

20. Visvader JE and Lindeman GJ: Cancer stem cells in solid tumours: accumulating evidence and unresolved questions. Nat Rev Cancer 8: 755-768, 2008.

21. Li C, Heidt DG, Dalerba P, et al: Identification of pancreatic cancer stem cells. Cancer Res 67: 1030-1037, 2007.

22. Costello RT, Mallet F, Gaugler B, et al: Human acute myeloid leukemia $\mathrm{CD} 34^{+} / \mathrm{CD} 38^{-}$progenitor cells have decreased sensitivity to chemotherapy and Fas-induced apoptosis, reduced immunogenicity, and impaired dendritic cell transformation capacities. Cancer Res 60: 4403-4011, 2000.

23. Dean M, Fojo T and Bates S: Tumour stem cells and drug resistance. Nat Rev Cancer 5: 275-284, 2005.

24. Guzman ML, Swiderski CF, Howard DS, et al: Preferential induction of apoptosis for primary human leukemic stem cells. Proc Natl Acad Sci USA 99: 16220-16225, 2002.

25. Mani SA, Guo W, Liao MJ, et al: The epithelial-mesenchymal transition generates cells with properties of stem cells. Cell 133: 704-715, 2008

26. Kurrey NK, Jalgaonkar SP, Joglekar AV, et al: Snail and slug mediate radioresistance and chemoresistance by antagonizing p53-mediated apoptosis and acquiring a stem-like phenotype in ovarian cancer cells. Stem Cells 27: 2059-2068, 2009.

27. Truty MJ and Urrutia R: Basics of TGF-beta and pancreatic cancer. Pancreatology 7: 423-435, 2007.

28. Ito D, Fujimoto K, Doi R, et al: Chronic exposure of transforming growth factor beta 1 confers a more aggressive tumor phenotype through downregulation of p21(WAF1/CIP1) in conditionally immortalized pancreatic epithelial cells. Surgery 136: 364-374, 2004. 